\title{
COMPARATIVE STUDY OF OUTCOMES BETWEEN LAPAROSCOPIC SINGLE ANASTOMOSIS SLEEVE ILEUM BYPASS (SASI BYPASS) VERSUS LAPAROSCOPIC MINI-GASTRIC BYPASS IN MORBID OBESE PATIENTS
}

\author{
By \\ Shawky Mohamed Deabes, Mohamed Abd-Elal Nafh andAhmed
Mohamed Salem Yehia \\ Department of general Surgery, Faculty of Medicine, Al-Azhar University, Egypt \\ E-Mail: ahmsurg182@yahoo.com
}

\begin{abstract}
Background: The single anastomosis sleeve ileal (SASI) bypass is a Novel Metabolic/Bariatric Surgery operation based on mini gastric bypass operation and Santoro's operation in which a sleeve gastrectomy is followed by a side to side gastro-ileal anastomosis.

Objective: To evaluate the short-term outcomes between laparoscopic single anastomosis sleeve ileal bypass and mini gastric bypass, with respect to postoperative weight loss and metabolic and nutritional effects on patients.

Patients and methods: This study was done at Al-Azhar University Hospital and Al-Nhar Hospital. It was a prospective randomized study which compared between single anastomosis sleeve ileum bypass (SASI bypass) Versus Laparoscopic Mini-gastric Bypass, in outcome. The study included 40 patients scheduled for elective laparoscopic bariatric surgery, due to morbid obesity, divided into two groups. The first group (group A) was operated by gastric mini bypass and the second group (group B) where single anastomosis sleeve ileum bypass was done.
\end{abstract}

Results: The results of the study revealed that that there was high significant difference between before and after SASI surgery as regard FBG, HbAIC, triglycerides, cholesterol, HDL and LDL. Conclusion: SASI bypass is a promising operation that offers excellent weight loss and diabetic resolution.

Keywords: SASI, Bariatric, Mini-gastric, laparoscopic, anastomosis, sleeve, prospective, bypass.

\section{INTRODUCTION}

The words 'obese-obesity' come to English via French from the Latin, where the verb 'obedere' means 'over eat' and 'obese' means being very fat (Thomas, $B$. 2010).

In practice, obesity is diagnosed by body mass index (BMI), which is taken as a surrogate of percentage fat mass. However, BMI has some obvious limitations related to the assessment of fat mass as well as the diagnosis of overweight and obesity-related disturbances. BMI is a score rather than objectively measured fat mass (or fat mass-related mechanical and metabolic disturbances) (Müller et al., 2016).

Obesity is a complex health issue to address. Obesity results from a combination of causes and contributing 
factors, including individual factors such as behavior and genetics. Behaviors can include dietary patterns, physical activity, inactivity, medication use, and other exposures. Additional contributing factors in our society include the food and physical activity environment, education and skills, and food marketing and promotion (Hall et al., 2011).

Treatment of obesity starts with comprehensive lifestyle management (i.e. diet, physical activity, behavior modification), which should include the following: Self-monitoring of caloric intake and physical activity, goal setting, stimulus control, nonfood rewards, relapse prevention. Few drugs are available for the treatment of obesity, and their effectiveness is limited to palliation (i.e. production and maintenance of weight loss) rather than cure, with benefits fading when the drugs are stopped, because all medications inherently have more risks than diet and exercise do, pharmacologic therapy should be used only in patients in whom the benefit justifies the risk (Abell and Minocha, 2016).

Bariatric surgery is the only intervention that gives long-standing improvement or resolution of obesityrelated conditions and also survival benefit. It is highly cost-effective. Surgical procedures for the treatment of obesity can be divided into three general categories: malabsorptive procedures, restrictive procedures and combined malabsorptive/ restrictive procedure (Mancini, 2014).

The mini-gastric bypass, or single anastomosis gastric bypass, is an effective and well-established procedure which combines some of the properties of a gastric sleeve and a standard gastric bypass. The upper part of the stomach is divided into a tube, similar to the top three quarters of a sleeve, and then joined to a loop of intestine (Balsiger et al., 2012).

The mini-gastric bypass can be used as a primary weight loss procedure. It can also be used in patients who have had previous gastric banding or sleeve surgery, but have been unsuccessful with weight loss, or who have had band-related complications and have decided on revision surgery (Greco, 2017).

Single anastomosis sleeve ileal bypass (SASI) procedure appears as a new metabolic and bariatric surgery based on Santoro's operation, in which a sleeve gastrectomy is followed by a side-to-side gastroileal anastomosis (Santoro et al., 2016).

This study aimed to evaluate the shortterm outcomes between laparoscopic single anastomosis sleeve ideal bypass and mini gastric bypass with respect to postoperative weight loss and metabolic and nutritional effects on patients.

\section{PATIENTS AND METHODS}

This study had been done at Al-Azhar University hospital and Al-Nhar Hospital. It was a prospective randomized study which had been compared between single anastomosis sleeve ileum bypass (SASI bypass) Versus Laparoscopic Mini-gastric Bypass, in outcome. The study included 40 patients scheduled for elective laparoscopic bariatric surgery, due to morbid obesity and divided into two equal groups. The first group (group A) was operated by gastric mini bypass, and the second group (group B) was operated by 
single anastomosis sleeve ileum between May, 2018 and December 2019

\section{Inclusion criteria:}

1. Morbidity obese patients satisfying the criteria for bariatric surgery.

2. First stage procedure for super obese.

3. High risk patients where duration of procedure affected morbidity and mortality.

\section{Exclusion criteria:}

Patients with absolute or relative contraindication to laparoscopy, malignancy, liver cirrhosis with portal hypertension, and alcohol abuse.

All patients were subjected to the following:

\section{A. History taking:}

- Detailed history for all patients

- A designed sheet was fulfilled for every patient to document his data.

Past history of previous interventions.

\section{B. Clinical examination:}

General: Blood pressure, pulse, cardiovascular, neurological and respiration assessment.

Local: Clinical assessment of the patient.

\section{Investigations:}

i. Laboratory workup: Hematologic and biochemical tests: complete blood count, fasting blood glucose, hemoglobin Alc, creatinine, fasting lipid profile, and urine analysis (for glycosuria and proteinuria).

ii. Duplex study, CT angiography,and cardiological assessment byresting electrocardiogram

and

echocardiography.

Informed consents were obtained from all patients after describing the operative and postoperative details and complications.

Routine gastroscopy was performed and abdominal ultrasound to exclude gallstones and to evaluate the degree of fatty liver.

The primary outcomes were the percent age of excess weight loss (\% EWL), resolution of diabetes and improvement of comorbidity. The percent age of EWL was calculated as follows: (preoperative weight-follow up weight)/ Preoperative excess weight $\times 100$. The amount of blood loss during operation was estimated by suction device.

Resolution of comorbidity was considered if the disease was controlled without any medications.

Secondary outcomes were postoperative complications, postoperative nutritional status and multivitamins intake which include regular daily intake one tablet of (Centrum, Feroglobin, and Calcium)

And every month intake (Vit.B Complex and Vit. D 200,000 unit) measuring level of vitamins at 3,6,12 months.

Postoperative care: Patients were kept nil by mouth under supervision of critical care specialist and motivated for early ambulation, usually 6-8 hours after surgery. Meanwhile, compression stockings and low molecular heparin are continued along with spirometry and chest physiotherapy. On first postoperative day, 
patients were allowed clear sips of liquid once every 10-15 min. Patients were discharged on 2nd or 3rd postoperative day with oral dispersible medicines depending on general condition, hydration, and on drain status.

\section{Statistical analysis of the data:}

Statistical analysis was done using IBM SPSS Statistics version 22 (IBM CORP., Armonk, NY, USA). Numerical data were expressed as mean and standard deviation or median and range as appropriate. Qualitative data were expressed as frequency and percentage. Chi-square test was used to examine the relation between qualitative variables. For quantitative data, comparison between two groups was done using independent sample t-test or Mann Whitney test. Furthermore, the overall of the comparison study was assessed by computing summary estimates of sensitivity, specificity, positive and negative predictive values (PPV and NPV). A p-value $<0.05$ was considered significant.

\section{RESULTS}

The mean age of the patients at the time of operation was $38.3 \pm 3.61$ years gastric mini bypass group versus $38.9 \pm$ 3.4 years for single anastomosis sleeve ileum bypass group. There was no significant difference between the studied groups as regard baseline data (Table1).

Table (1): Baseline data in between the studied groups

\begin{tabular}{|c|c|c|c|c|c|c|}
\hline Variables & \multicolumn{2}{|c|}{$\begin{array}{c}\text { Group1 } \\
(\mathbf{n}=20)\end{array}$} & \multicolumn{2}{|c|}{$\begin{array}{c}\text { Group2 } \\
(\mathbf{n}=20)\end{array}$} & T test & $P$ value \\
\hline \multicolumn{7}{|l|}{ Age: (Years): } \\
\hline $\begin{array}{l}\text { Mean } \pm \text { SD } \\
\text { Range }\end{array}$ & \multicolumn{2}{|c|}{$\begin{array}{c}38.3 \pm 3.61 \\
(32-47)\end{array}$} & \multicolumn{2}{|c|}{$\begin{array}{c}38.9 \pm 3.4 \\
(31-46)\end{array}$} & 0.928 & 0.887 \\
\hline \multicolumn{7}{|l|}{ BMI } \\
\hline $\begin{array}{l}\text { Mean } \pm \text { SD } \\
\text { Range }\end{array}$ & \multicolumn{2}{|c|}{$\begin{array}{l}48.7 \pm 7.6 \\
(39-54)\end{array}$} & \multicolumn{2}{|c|}{$\begin{array}{c}47.9 \pm 6.9 \\
(38-54)\end{array}$} & 1.23 & 0.712 \\
\hline & No. & $\%$ & No. & $\%$ & $\chi^{2}$ & P value \\
\hline \multicolumn{7}{|l|}{ Gender } \\
\hline $\begin{array}{l}\text { Female } \\
\text { Male }\end{array}$ & $\begin{array}{l}10 \\
10 \\
\end{array}$ & $\begin{array}{l}50.0 \\
50.0\end{array}$ & $\begin{array}{c}9 \\
11 \\
\end{array}$ & $\begin{array}{l}45.0 \\
55.0 \\
\end{array}$ & 0.092 & 0.911 \\
\hline
\end{tabular}

There was no significant difference between the studied groups as regard comorbidities (Table 2). 
COMPARATIVE STUDY OF OUTCOMES BETWEEN LAPAROSCOPIC... 961

Table (2): Comorbidities distribution among the studied groups

\begin{tabular}{|c|c|c|c|}
\hline $\begin{array}{ll}\text { Variables } & \text { Groups } \\
\end{array}$ & $\begin{array}{c}\text { Group1 } \\
(\mathrm{n}=20)\end{array}$ & $\begin{array}{c}\text { Group2 } \\
(\mathrm{n}=\mathbf{2 0})\end{array}$ & P-value \\
\hline \multicolumn{3}{|l|}{ Diabetes mellitus } & \multirow{3}{*}{0.056} \\
\hline Yes & $8(40 \%)$ & $14(70 \%)$ & \\
\hline No & $12(60 \%)$ & $6(30 \%)$ & \\
\hline \multicolumn{3}{|l|}{ Hypertension } & \multirow{3}{*}{0.197} \\
\hline Yes & $6(30 \%)$ & $10(50 \%)$ & \\
\hline No & $14(70 \%)$ & $10(50 \%)$ & \\
\hline
\end{tabular}

After 12 months, $75 \%$ of patient weaned from the four types of multivitamins regimen to one multivitamin regimen without apparent nutritional deficiency with high significant difference between the two techniques as regard multivitamins regimen (Fig 1).

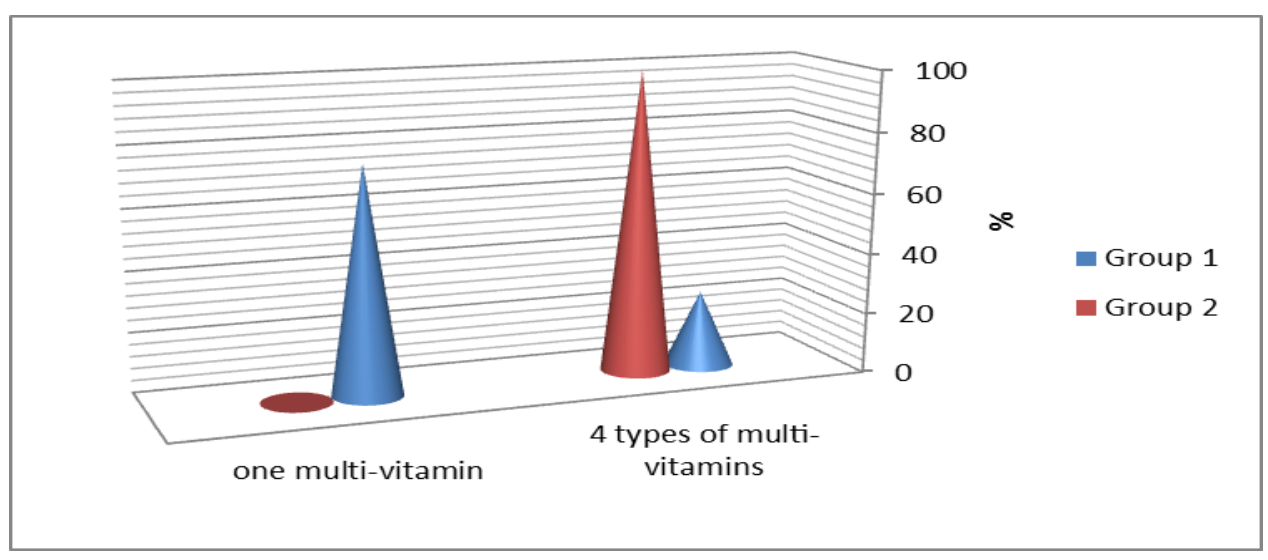

Fig(1):Comparison between the studied groups as regard multivitamins intake after 12 months

There was no significant difference between the two included techniques as regard duration of surgery (Fig 2).

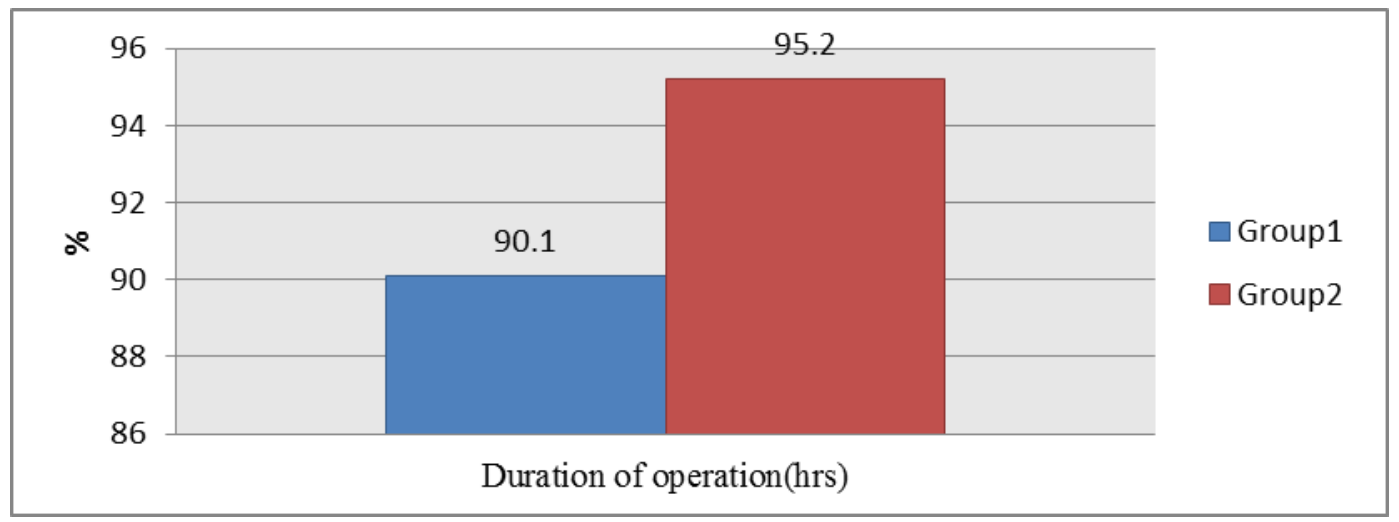

Fig (2): Mean duration of operation of the studied groups

There was a significant difference between before and after surgery as regard
FBG, HbAIC, triglyceride, cholesterol, HDL and LD (Table 3). 
Table (3): Pre and postoperative mean values in SASI group

\begin{tabular}{|c|c|c|c|c|c|}
\hline Variables & $\begin{array}{c}\text { Pre- } \\
\text { operative }\end{array}$ & $\begin{array}{c}3 \text { months } \\
\text { post- } \\
\text { operative }\end{array}$ & $\begin{array}{c}6 \text { months } \\
\text { post- } \\
\text { operative }\end{array}$ & $\begin{array}{c}12 \text { months } \\
\text { post- } \\
\text { operative }\end{array}$ & $\begin{array}{c}\mathbf{P} \\
\text { value }\end{array}$ \\
\hline \multicolumn{6}{|l|}{ FBS (mg/dl): } \\
\hline Mean \pm SD & $169.2 \pm 74.2$ & $109.5 \pm 11.8$ & $101 \pm 9.8$ & $85 \pm 11.8$ & $<0.001$ \\
\hline \multicolumn{6}{|l|}{ HbA1c (\%): } \\
\hline Mean \pm SD & $9.9 \% \pm 2.7 \%$ & $6.1 \% \pm 0.7 \%$ & $5.7 \pm 0.8 \%$ & $5.1 \pm 0.8 \%$ & $<0.001$ \\
\hline \multicolumn{6}{|c|}{ Triglycerides $(\mathrm{mmol} / \mathrm{L})$} \\
\hline Mean \pm SD & $2.7 \pm 0.7$ & $1.4 \pm 0.6$ & $1.1 \pm 0.2$ & $1.2 \pm 0.4$ & $<0.001$ \\
\hline \multicolumn{6}{|c|}{ Cholesterol $(\mathrm{mmol} / \mathrm{L})$} \\
\hline Mean \pm SD & $6.9 \pm 1.8$ & $4.6 \pm 0.9$ & $3.9 \pm 1.2$ & $3.1 \pm 1.1$ & $<0.001$ \\
\hline \multicolumn{6}{|c|}{ HDL (mmol/L) } \\
\hline Mean \pm SD & $1.2 \pm 0.9$ & $2.3 \pm 0.8$ & $2.5 \pm 1.9$ & $2.9 \pm 1.2$ & $<0.001$ \\
\hline \multicolumn{6}{|c|}{ LDL (mmol/L) } \\
\hline Mean \pm SD & $4.9 \pm 1.9$ & $2.5 \pm 0.8$ & $2.2 \pm 0.9$ & $2.1 \pm 0.8$ & $<0.001$ \\
\hline
\end{tabular}

There was a significant difference between before and after surgery as regard
FBG, HbAIC, triglyceride, cholesterol, HDL and LDL (Fig 3).

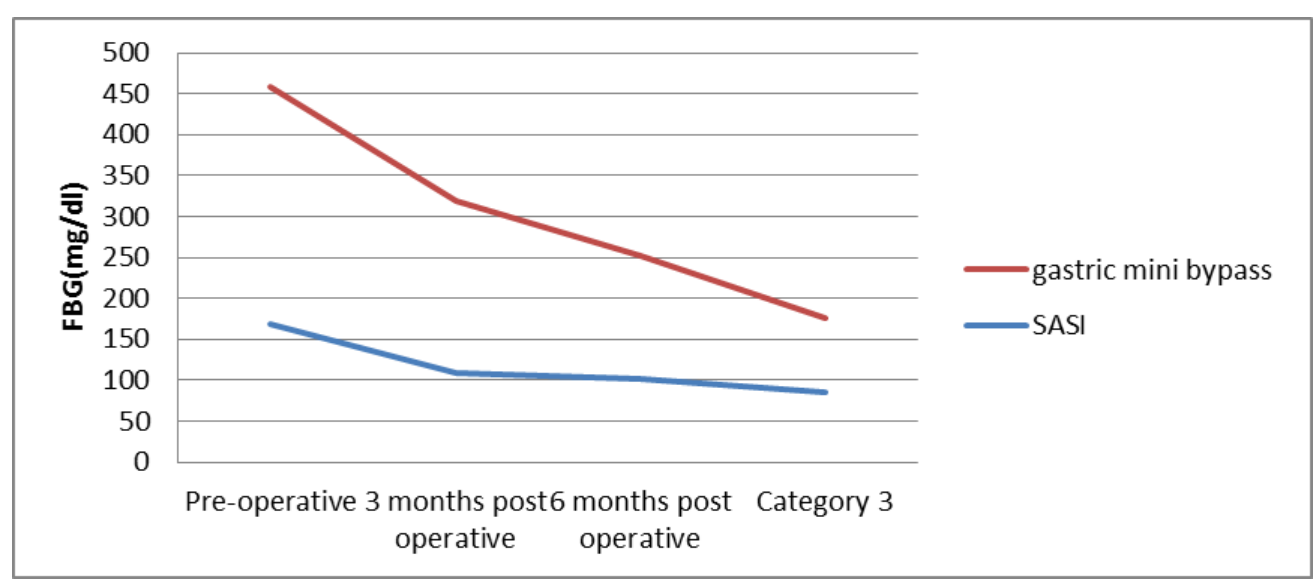

Fig (3): Overtime change in FBG in both groups

There was a significant difference between the two included techniques as regard amount of blood loss during operation (Fig 4). 


\section{COMPARATIVE STUDY OF OUTCOMES BETWEEN LAPAROSCOPIC... 963}

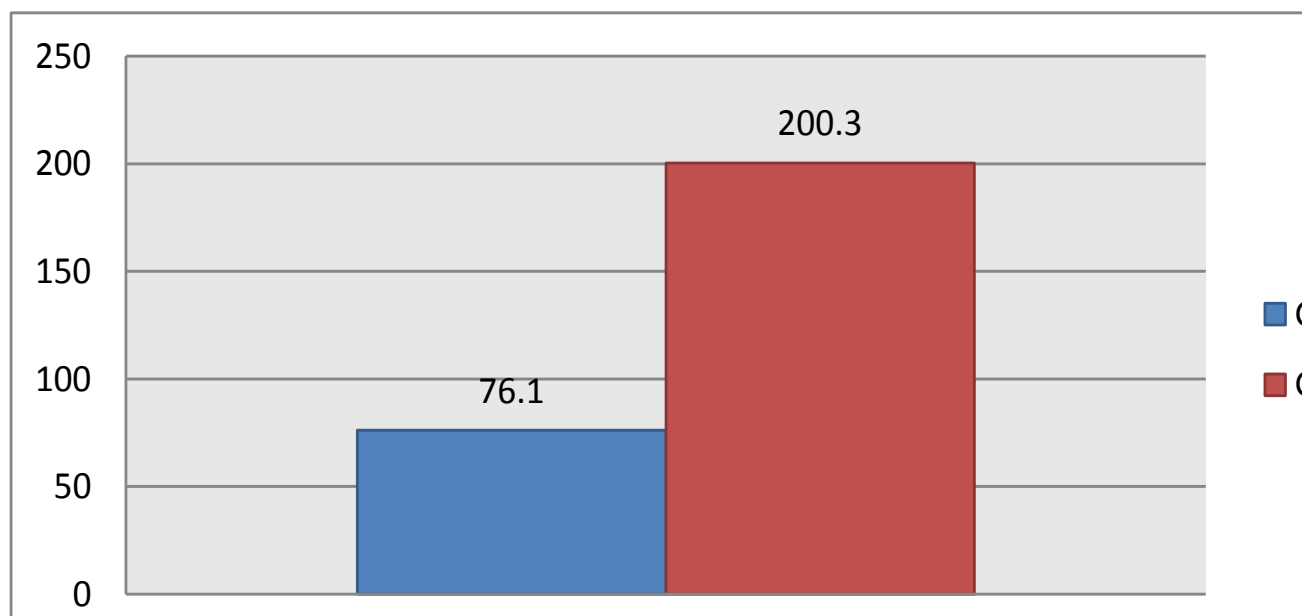

Fig (4): Mean amount of blood loss during operation of the studied groups

There was no significant difference between the two studied groups as regard complications (Table 4).

Table (4): Comparison between the studied groups as regard complications

\begin{tabular}{|c|c|c|c|c|c|}
\hline \multirow[t]{2}{*}{ Variables Groups } & \multicolumn{2}{|c|}{$\begin{array}{c}\text { Group1 } \\
(\mathrm{n}=20)\end{array}$} & \multicolumn{2}{|c|}{ Group2 $(n=20)$} & \multirow[t]{2}{*}{$P$ value } \\
\hline & No. & $\%$ & No. & $\%$ & \\
\hline \multicolumn{6}{|l|}{ During surgery: } \\
\hline $\begin{array}{l}\text { Leak during Methylene } \\
\text { blue test } \\
\text { Convert to open }\end{array}$ & $\begin{array}{l}0 \\
0\end{array}$ & $\begin{array}{l}0.0 \\
00\end{array}$ & $\begin{array}{l}2 \\
0\end{array}$ & $\begin{array}{c}10.0 \\
0.0\end{array}$ & 0.723 \\
\hline \multicolumn{6}{|l|}{ Post-operative: } \\
\hline Bleeding & 0 & 0.0 & 1 & 5.0 & \\
\hline Stenosis & 1 & 5.0 & 0 & 0.0 & \\
\hline Biliary gastritis & 0 & 0.0 & 0 & 0.0 & 0.893 \\
\hline Leak & 0 & 0.0 & 0 & 0.0 & \\
\hline
\end{tabular}

\section{DISCUSSION}

Obesity is a worldwide epidemic. Morbidly obese subjects are at risk of numerous physical and metabolic comorbidities that severely impair their health and increase mortality (Flegal et al., 2012).

Bariatric surgery not only allows sustained weight loss, but also reduces comorbidities and improves survival.
Therefore, it is not surprising that the number of bariatric surgeries worldwide has grown rapidly over the past decades (Buchwald and Oien, 2013).

There was no significant difference between the studied groups as regard baseline data.

Our results were in agreement with study of Khalil et al. (2019) as they found that there was no significant difference between the two groups regarding sex distribution. 
Our results were supported by the study of Mahdy et al. (2016) as they reported that 50 patients were evaluated, 33 women, and 17 men, with a mean BMI of $48.7 \pm 7.6 \mathrm{~kg} / \mathrm{m} 2$, mean age $40.5 \pm 7.9$ years.

The present study showed that there was no significant difference between the studied groups as regard comorbidities.

Our results were in line with study of Khalil et al. (2019) as they reported that among the common obesity-related comorbidities, diabetes was seen in $100 \%$ of all patients, followed by hypertension $(19.6 \%)$ and hyperlipidemia (13.7\%). There was no significant difference between the studied groups regarding comorbidities.

Furthermore, Noun et al. (2012) found that comorbidities were present in $26.5 \%$ patients, and included diabetes (19\%), hyperlipidemia $(24.6 \%)$, hypertension (23\%), sleep apnea (17.8\%), arthritic pain (22\%), gastroesophageal reflux (21\%). There were no significant differences between the studied groups regarding comorbidities.

According to Lee et al. (2015) metabolic syndrome as defined by the ATPIII criteria affected $56 \%$ of the morbidly obese patients in this trial. There was no significant difference between the studied groups regarding comorbidities.

Our results were supported by the study of Mahdy et al. (2016) as they reported that the mean operative time was $114 \pm 30.5 \mathrm{~min}$.

Our results were in contrary with study of Khalil et al. (2019) as they reported that the mean operative times were significantly different compared among studied groups. In laparoscopic sleeve gastrectomy with loop bipartition, the majority of nutrients and food mainly pass through gastroileostomy rather than physiological pathway, and this observation is functionally similar to single anastomosis duodenal-ileostomy and duodenal-jejunal bypass, with less nutritional and surgical complications.

According to Lee et al. (2015), there was asignificant difference in operation time among studied groups. Surgical time was significantly different among studied groups.

As regard glycemic and lipid profile pre and postoperative mean values in SASI group, in the study in our hands, there was a high significant difference between before and after surgery as regard FBG, HbAIC, triglycerides, cholesterol, HDL and LDL.

Our results were in agreement with study of Mahdy et al. (2016) as they reported that there was a significant difference between before and after surgery as regards FBG, HbAIC, triglyceride, cholesterol, HDL and LDL.

Furthermore Khalil et al. (2019) found that the laparoscopic sleeve gastrectomy with loop bipartition) group had significantly lower fasting blood glucose and glycated hemoglobin (HbA1c) levels in 1 month, 3 months, 6 months, and 12 months postoperatively.

As regard glycemic and lipid profile pre and postoperative mean values in gastric mini bypass group, the present study showed that there were significant differences between before and after surgery as regard FBG, HbAIC, triglyceride, cholesterol, HDL and LDL. 


\section{COMPARATIVE STUDY OF OUTCOMES BETWEEN LAPAROSCOPIC... 965}

Our results were in agreement with study of Lee et al. (2015) as they reported that there was a significant difference between before and after surgery as regard $\mathrm{Hb}$. In their study, MGB proved to be effective in the long term, significantly outperforming even RYGB in several parameters including BMI reduction, resolution of metabolic syndrome, and the need for revision surgery due to both bowel obstruction and internal hernia.

According to Musella et al. (2014) there was a significant difference between before and after surgery regarding control of DM.

The present study showed that there was a significant difference between the two included techniques as regard amount of blood loss during operation. There was no significant difference between the two studied groups as regard complications.

Our results were in agreement with study of Sayadishahraki et al. (2019) as they found that there was no significant difference between the two studied groups as regard complications.

Furthermore, Khalil et al. (2019) reported that no significant difference between the two groups regarding postoperative complications and hospital stay. Only two patients with an internal hernia required reoperation. Other patients underwent endoscopic and conservative treatments for other postoperative complications.

Our results were supported by study of Mahdy et al. (2016) as they reported that an adequate initial weight loss was predicted; because the function restrictive component of the operation was, a sleeve gastrectomy and the gastro-ileal bypass induce neuroendocrine modulation. Thus, in terms of weight loss and co-morbidities resolution, SASI bypass initially provides satisfactory results. The weight loss was excellent from the beginning. The percentage of excess weight loss (\% EWL) was $75 \%$ by the first 6 postoperative months and had reached a mean value of $90 \%$ at 12 months postoperatively.

These data were maintained during the whole follow-up period and were significantly greater than those obtained with other bariatric procedures (Alobaid et al., 2015). Previous versions of the BPD and the DS (duodenal switch) had achieved a long-term (10 y) \% EWL of 70-80\% (Ceneviva et al., 2018).

In the follow-up study by Daniel et al. (2017) a maximum weight loss was obtained by the third postoperative year and then patients regained minimally and to plateau around $75 \%$ EWL in the long term. In contrary, our patients reached a greater peak earlier that could have been attributed to the greater gastric function restriction.

Carvalho et al. (2012) observed that there was no significant difference between both groups regarding anemia, vitamins deficiency, and hypoalbuminemia, and these were still low in comparison with other bariatric bypass operations owing to the elimination of two ways of food passage. The postoperative undernutrition program makes patient malnutrition evaluation difficult.

Regarding Sánchez-Pernaute et al. (2010), there were no intraoperative complications. Two gastric leaks (4\%) presented one of them visible only in the 
barium swallow, while the other had a clinical repercussion. The stomach thickness, along with technical errors in the gastric stapling, is responsible for these leaks. Currently they protected the staple line with an invaginating serosa-toserosa running suture, as recommended by Baltasar et al. (2017) and they covered it with hemostatic sponges. No leaks have been detected in the duodeno-ileal anastomosis or in the duodenal stump, which is never invaginated.

Regarding Lee et al. (2015), LRYGB had significant higher complication rate in bowel obstruction and major bleeding. There was no difference in the mortality rate. Musella et al. (2014) reported that the postoperative complications that occurred within the first 30 days. An early surgical revision was required for $2 \%$ of the patients. A liquid diet was started for all the patients at $2.5 \pm 1.1$ postoperative days.

Also, Noun et al. (2012) reported that in primary MGB, the complication rate was $2.7 \%$ and $11.9 \%$ for revisional MGB in forms of bleeding, leakage and stenosis. The mean length of hospital stay was comparable for patients with Lap MGB or Mini-open MGB but was significantly shorter for patients with primary vs. revisional MGB.

Geraldo et al. (2014) found that early complications $(4.3 \%)$ were encountered, and 7 major complications (1.7\%) occurred. Marginal ulcers were noted in $8.0 \%$ during follow-up, and anemia was found in 9.7\%. Solouki et al. (2018) reported that the complications included gastrojejunostomy leak in 3, bile reflux in 20, intractable marginal ulcer in 5, malabsorption /malnutrition in 8 , and weight gain in 2 .

Limitations of this study included the small number of patients and short followup period. The data in the present study remained preliminary and feasibility of this surgical procedure on a large scale requires a lot of hard work.

\section{CONCLUSION}

SASI bypass is a promising operation, based on digestive adaptation physiologic principles, easier to perform than the Santoro's operation and BPD modifications, and with very good results as duodenal switch operation in the short run without malabsorption morbidity. The absence of prostheses or excluded segments, full endoscopic access, and easy feasibility associated with an excellent weight loss and diabetic resolution. Confirmation of these data and longer follow-up would strengthen the case for the consideration of SASI bypass as the most appropriate metabolic surgery procedure.

\section{REFERENCES}

1. Abell TL and Minocha A. (2016): Gastrointestinal complications of bariatric surgery: diagnosis and therapy, Am. J. Med. Sci, 331 (4): $214-8$.

2. A, Alsadoon K.M and Eltawil $H$. (2015): Bariatric surgery for obesity: a systematic review and meta-analysis. Adv. Obes. Weight Manag. Control, 2 (2) : 00011-43

3. Balsiger BM, Kennedy FP and AbuLebdeh HS. (2012): Prospective evaluation of Roux-en-Y gastric bypass as primary operation for medically complicated obesity. Mayo Clin Proc., 75: 673-680. 
4. Baltasar A, Aniceto R, Bengochea $M$, Serra C, Perez N, Arlandis F, Martinez $R$ and Cipagauta L. (2017): Four Decades of Bariatric Surgery in a Community Hospital of Spain. Journal of Obesity and Weight Loss Therapy, 41:244-51.

5. Buchwald H and Oien DM. (2013): Metabolic/bariatric surgery worldwide. Obes Surg., 23(4):427-36.

6. Carvalho IR, Loscalzo Z, Freitas M, Fernandes B, Jordão, RE and Friano TD. (2012): Incidence of vitamin B12 deficiency in patients submitted to FobiCapella Roux-en-Y bariatric surgery. ABCD. Arquivos Brasileiros de Cirurgia Digestiva (São Paulo), 25(1): 36-40.

7. Ceneviva $R$ and Salgado Junior $W$. (2018): Surgical Treatment for Severe Protein-Calorie Malnutrition after Bariatric Surgery. In: Preedy V., Patel V. (eds) Handbook of Famine, Starvation, and Nutrient Deprivation. Springer, Cham, 31:933-9.

8. Daniel $\mathbf{C}$, Galvao $\mathbf{N}$ and Josemberg $\mathbf{M}$ C (2017): Gastric Imbrication: Opinions General Surgery News. 38:7- 53.

9. Flegal KM, Carroll MD and Kit BK. (2012): Prevalence of obesity and trends in the distribution of body mass index among US adults, 1999-2010. JAMA J Am Med Assoc, 307 (5):491-7.

10. Geraldo S, Fonseca FL, Gouveia MR and Feder D. (2014): The complications in patients undergone bariatric surgery. Int J Gen Med., 7:219-224.

11. Greco F. (2017): Conversion of Vertical Sleeve Gastrectomy to a Functional Single-Anastomosis Gastric Bypass: Technique and Preliminary Results Using a Non-Adjustable Ring Instead of Stapled Division. Obesity Surgery, 27(4): 896-901.
12. Hall KD, Sacks $G$ and Chandramohan D. (2011): Swinburn BA. Lancet, 27; 378 (9793): 826-37.

13. Khalil O, Mansy $H$ and Abdalla WS. (2019): Laparoscopic sleeve gastrectomy with loop bipartition versus laparoscopic sleeve gastrectomy in treating obese people with type II diabetes mellitus: a prospective randomized comparative study. The Egyptian Journal of Surgery, 38(3); 610-9.

14. Lee WJ, Almulaifi $A$ and Tsou JJ. (2015): Laparoscopic sleeve gastrectomy for type 2 diabetes mellitus: predicting the success by ABCD score. Surg Obes Relat Dis., 11:991-6.

15. Mancini C. (2014): Bariatric surgery An update for the endocrinologist. Arquivos Brasileiros de Endocrinologia \& Metabologia, 58 (9): 875-888.

16. Mahdy T, Al Wahedi A and Schou C. (2016): Efficacy of single anastomosis sleeve ileal (SASI) bypass for type-2 diabetic morbid obese patients: Gastric bipartition, a novel metabolic surgery procedure A retrospective cohort study. Int J Surg., 34:28-34.

17. Müller MJ, Braun W and Enderle J. (2016): Beyond BMI: conceptual issues related to overweight and obese patients. Obes Facts, 9: 193-205.

18. Musella M, Susa $A$ and Greco $F$. (2014): The laparoscopic mini-gastric bypass: the Italian experience: outcomes from 974 consecutive cases in a multicenter review. Surgical Endoscopy, 28(1): 156-163.

19. Noun R, Skaff J and Riachi E. (2012): One thousand consecutive mini-gastric bypass: short-and long-term outcome. Obesity Surgery, 22(5): 697-703.

20. Sánchez-Pernaute A, Herrera, and Pérez-Aguirre ME (2010): Single anastomosis duodeno-ileal bypass with 
sleeve gastrectomy (SADI-S). One to three-year follow-up. Obesity Surgery, 20(12): 1720-1726.

21. Santoro S, Malzoni CE, Velhote MC, Milleo FQ, Santo MA and Klajner S. (2016): Digestive adaptation with intestinal reserve: a neuroendocrinebased operation for morbid obesity. Obes Surg., 16:1371-1379.

22. Sayadishahraki M, Rezaei $M$ and Mahmoudieh T. (2019): SingleAnastomosis Sleeve Jejunal Bypass, a Novel Bariatric Surgery, Versus Other Familiar Methods: Results of a 6-Month
Follow-up - a Comparative Study. Obesity Surgery, 1-8-12

23. Solouki A, Kermansaravi M, Davarpanah Jazi A, Kabir A, Farsani T and Pazouki A. (2018): Oneanastomosis gastric bypass as an alternative procedure of choice in morbidly obese patients. Journal of research in medical sciences: the official journal of Isfahan University of Medical Sciences, 23:84-18.

24. Thomas B. (2010): Obesity in the world, and Nutrient Deprivation, Obesity Surgery, 41:406-12. 


\section{دراسة مقارنة بين نتائج عملية التحويل المصغر للمعدة وعملية

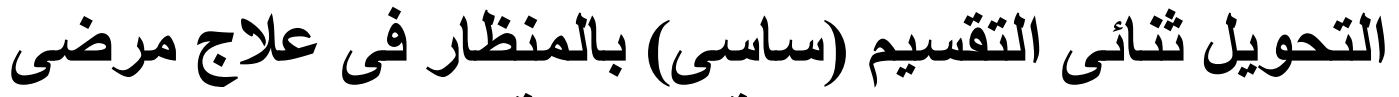 السمنة المفرطة)}

شوقي محمد دعبس، محمد عبدالعال نافع،أحمد محمد سالم

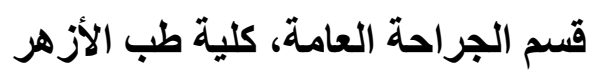

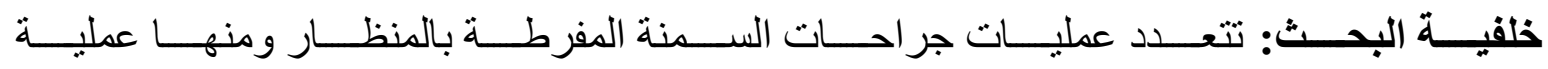

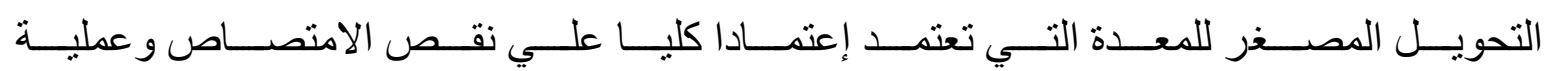

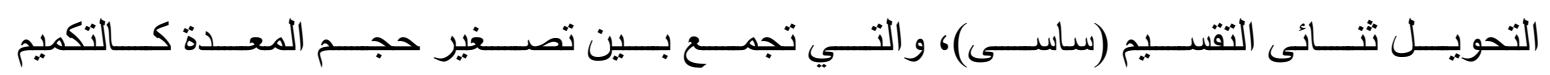
ونقص الإمتصاص أيضا كالتحويل.

الهـــف مــن البحــث: المقارنـــة بــين نتــائج عمليتــي التحويـلـ المصــغر و التحويـلـ ثتــائى

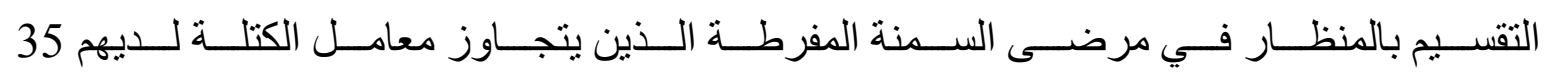
في مستشفيات جامعة الاز هر.

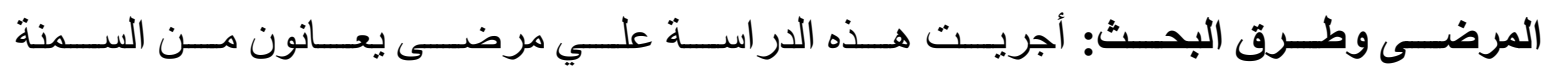

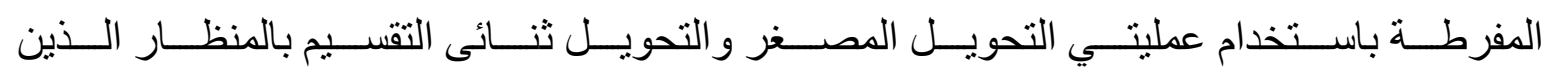

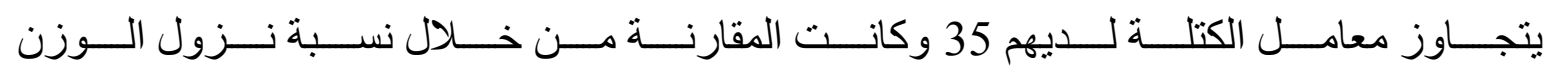

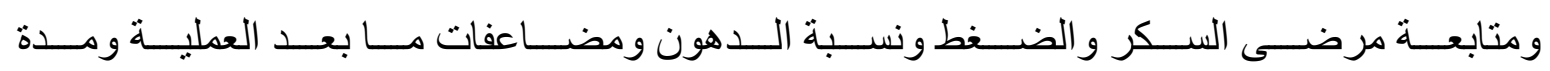

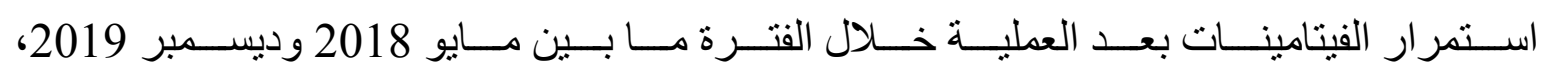
حيث تم فحص المرضى بعد شهر وثلاثة أنثهر وستة أثهر وبعد عام.

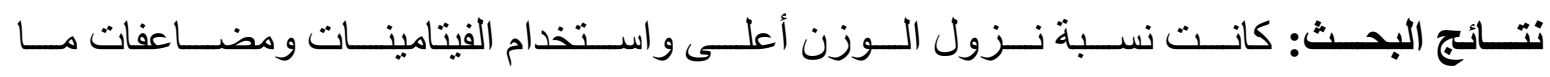

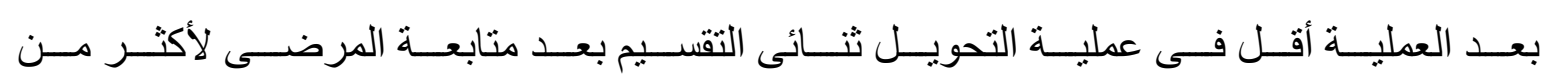
عام.

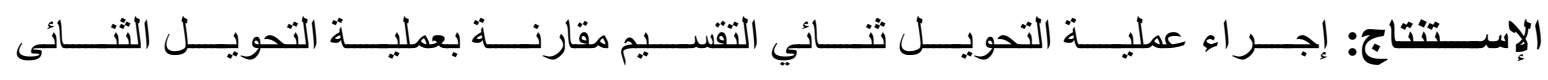

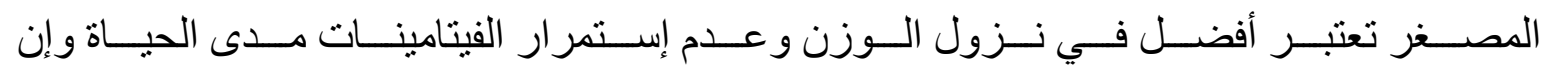
كان الأمر يحتاج إلي دراسات متقدمة وأوسع مجالا. 